\title{
Inhabiting the Antarctic
}

Jessica O’Reilly \& Juan Francisco Salazar

\section{Introduction}

The Polar Regions are places that are part fantasy and part reality. ${ }^{1}$ Antarctica was the last continent to be discovered (1819-1820) and the only landmass never inhabited by indigenous people. ${ }^{2}$ While today thousands of people live and work there at dozens of national bases, Antarctica has eluded the anthropological imagination. In recent years, however, as anthropology has turned its attention to extreme environments, scientific field practices, and ethnographies of global connection and situated globalities, Antarctica has become a fitting space for anthropological analysis and ethnographic research. $^{3}$

The idea propounded in the Antarctic Treaty System - that Antarctica is a place of science, peace, environmental protection, and international cooperation-is prevalent in contemporary representations of the continent. Today Antarctic images are negotiated within a culture of global environmentalism and international science. Historians, visual artists, and journalists who have spent time in the Antarctic have provided rich accounts of how these principles of global environmentalism and

\footnotetext{
${ }^{1}$ See for instance Adrian Howkins, The Polar Regions: An Environmental History (Cambridge, UK: Polity, 2016).

${ }^{2}$ Archaeological records have shown evidence of human occupation of Patagonia and the South American sub-Antarctic region $\left(42^{\circ} \mathrm{S}\right.$ to Cape Horn $\left.56^{\circ} \mathrm{S}\right)$ dating back to the Pleistocene-Holocene transition $\left(13,000-8,000\right.$ years before present). The first human inhabitants south of $60^{\circ} \mathrm{S}$ were British, United States, and Norwegian whalers and sealers who originally settled in Antarctic and sub-Antarctic islands during the early 1800 s, often for relatively extended periods of time, though never permanently ${ }^{3}$ See for instance Jessica O'Reilly, The Technocratic Antarctic: An Ethnography of Scientific Expertise and Environmental Governance (Ithaca, NY: Cornell University Press, 2017); Juan Francisco Salazar, "Geographies of Place-making in Antarctica: An Ethnographic Approach," The Polar Journal 3, no. 1 (2013): 53-71.
} 
international science shape everyday life in Antarctic research stations. While Antarctica has remained off bounds to ethnographers, we argue that anthropologically inflected ethnographic research is useful to cultivate a deeper sense of the life-worlds unfolding in Antarctic places. As human populations increasingly make themselves at home in Antarctica, it is relevant to ask ourselves what are the kinds of socialities, material cultures, intangible heritage and cultural practices emerging there.

As Tim Ingold has noted, anthropology ought to be "an enterprise energized by the tension between speculative inquiry into what life could be like and a knowledge, rooted in practical experience, of what life is like for people of particular times and places". ${ }^{4}$ Contemporary human life in the Antarctic holds, in the measure, these pragmatic and inventive ways of being, exemplifying Glasberg's search for "ways that Antarctica as geographic terminus has been made to stand for hope or for doom—and usually both at the same time". 5

During the past decade across several Antarctic sites and locations both on Ross Island, East Antarctica, and in the South Shetland Islands, Antarctic Peninsula, we have conducted ethnographic fieldwork from which we argue that a "well-developed attentiveness to location"6 and to modes of place-making in Antarctica is imperative to understanding the processes through which humans make themselves at home in Antarctic worlds, with each other, among their material cultures and infrastructures, and in relationship with other Antarctic living things and beings.

\footnotetext{
${ }^{4}$ Tim Ingold, “That's Enough About Ethnography!” HAU: Journal of Ethnographic Theory 4, no. 1 (2014): 383-95.

${ }^{5}$ Glasberg, Antarctica as Cultural Critique, : The Gendered Politics of Scientific Exploration and Climate Change (New York: Palgrave-Macmillan, 2012), xii.

${ }^{6}$ Akhil Gupta and James Ferguson, "Beyond 'Culture': Space, Identity, and the Politics of Difference," in Culture, Power, Place: Explorations in Critical Anthropology, eds. Akhil Gupta and James Ferguson, (Durham and London: Duke University Press, 1997), 36.
} 
In our ethnographic accounts that follow, the focus of our analysis is on the forms of sociality and subjectivity emerging in Antarctica. We ask, how do senses of place invoke experiences, conditions, things, dreams, landscapes, imaginaries, and lived sensory moments? How do people dwelling in Antarctic research stations become attuned to a "sense of something coming into existence or something waning, sagging, dissipating, enduring, or resonating with what is lost or promising"??

\section{Ethnographies of place in Antarctica}

The Antarctic is in fact a region not only composed of many distinctive ecosystems but also, as Alessandro Antonello observes, of spaces that "abut, overlap, compete, inter-connect, are separate and distinct, formal or informal, temporary or permanent, strictly or loosely bounded". ${ }^{8}$ This intellectual exercise of "disaggregating and disassembling the larger Antarctic space into smaller parts," provides as Antonello suggests, a window to analyse how in Antarctica, "complex and diverse environments sustain a multitude of human projects and activities that respond to and produce a variety of spaces."9

In other words, while Antarctic spaces and places are vividly imagined, their material geographies have garnered less attention and remain intrinsically elusive. Referring to this gap, Collis and Stevens noted over a decade ago that "beyond empirical studies of

\footnotetext{
${ }^{7}$ Kathleen Stewart, “Atmospheric Attunements." Environment and Planning D: Society and Space 29, no. 3 (2011): 445. See also Salazar, "Geographies of Place-making," 2013.

${ }^{8}$ Alessandro Antonello, "Finding Place in Antarctica." In Antarctica and the Humanities, pp. 181-203. Palgrave Macmillan UK, 2016. See also Meredith Hooper, The Ferocious Summer Adélie Penguins and the Warming of Antarctica (Vancouver, B.C.: Greystone Books, 2008), xvi.

${ }^{9}$ Ibid.
} 
the settlements' environmental impacts, and of the sociology of small groups in isolated environments, and beyond the mounting number of oral and written histories of individual Antarctic workers and visitors' experiences of Antarctica, the physical spatialities of Antarctican stations remain largely ignored." ${ }^{10}$ For these authors, grasping the complex spatiality of Antarctic settings required an understanding of the "concrete materiality which people have produced there, and the ways in which this spatial materiality is interlinked with social processes and meanings." 11

In this article we seek to contribute to what we perceive as an on-going lacuna by providing an account of our anthropologically informed ethnographic practices in Antarctica. In particular, while the concept of place has been well theorised, the notion of what it means to inhabit a place is, if considered at all, bound to ideas of locality and the seemingly intrinsic affect of being from a place.

In her ethnographic work in the Arctic, Kirsten Hastrup draws from Doreen Massey to note how "place itself is an event of configuration." 12 For Hastrup "places may be named and marked by completely different time scales, but they are the result of emerging stories, accidental encounters, and movements along lines of promise." 13 As Massey posited: "what is special about place is precisely that 'throwntogetherness, the unavoidable challenge of negotiating the here-and-now (itself drawing on a history and a geography of thens and theres); and a negotiation that must take place between

\footnotetext{
${ }^{10}$ Christy Collis and Quentin Stevens, "Cold Colonies: Antarctic Spatialities at Mawson and McMurdo Stations," Cultural Geographies 14, no. 2 (2007): 235.

${ }^{11}$ Collis and Stevens, "Cold Colonies," 235.

${ }^{12}$ Kirsten Hastrup Anticipating Nature: The Productive Uncertainty of Climate Models, in The Social Life of Climate Change Models: Anticipating Nature, edited by Kirsten Hastrup and Martin Skrydstrup (London and New York: Palgrave, 2013), 17.

${ }^{13}$ Hastrup 2013, 22.
} 
both human and non-human." 14 In other words, it is "the coming together of the previously unrelated, a constellation of processes rather than a thing. This is place as open and multiple. Not capturable as a slice through time in the sense of an essential section. Not intrinsically coherent." 15

We propose to forward notions of inhabitation as something intentional, built by humans both from top-down governmental practices and bottom-up improvisations of everyday Antarctic life. In particular, Antarctic places emerge through four sets of human relationships: 1) with particular populations of human bodies, 2) through the performance of geopolitics, 3) with the natural environment, and 4) through varied technological practices.

The extreme environments of Antarctica enable us to examine ethnographically the social fields of extremity as extensions of human histories, subjectivities, and socialities. ${ }^{16}$ An ethnographic attentiveness to Antarctic places, place-making, dwelling, and inhabitation furthers the methodological agenda of empirically mapping mobile, world-spanning connections, in ways that allow us to move considerations of Antarctica from the realm of abstract space to inhabited space. As Antarctic people inhabit their polar places, their place-work becomes attuned to the top-down governmental postures of Antarctic geopolitics. But more importantly, the everyday lives of everyday Antarctic people also resist this, creating other more quotidian, intimate places in research stations: this forms the core of inhabiting Antarctica.

\footnotetext{
${ }^{14}$ Doreen Massey For Space (Los Angeles and London: Sage 2005), 140.

15 Ibid, 141.

${ }^{16}$ For a discussion on the figure of the extreme in anthropology see David Valentine, Valerie A. Olson, and Debbora Battaglia, "Extreme: Limits and Horizons in the Once and Future Cosmos," Anthropological Quarterly 85, no. 4 (2012): 1007-26.
} 


\section{Inhabiting the Antarctic: Ethnographic Vignettes}

An important part of our previous research in Antarctica has been to understand how humans are learning to live on "the Ice." We have done this in several distinct ways. In the case of O'Reilly, it has been through looking at how Antarctic science and policymaking uses the cultures of scientific expertise to attempt to create a technocratic utopia, in which scientific knowledge rationally translates into sound policy. This is unattainable in practice, of course, but the intention behind this endeavour - and the idealistic, exceptionalist view that the Antarctic environment is like nowhere else on Earth—makes the partial fulfilment of these aspirational goals analytically productive. In Salazar's work it has been by examining social practices of inhabiting the extreme, including some of the relational cultural dynamics among transient inhabitants of international scientific and military stations, both of which include concomitant processes of making Antarctica familiar. Salazar uses the metaphor of living in Antarctica as a mode of "terraforming" the continent (in the sense of transforming Antarctica into a habitable world for humans), and also as a stepping-stone into modes of thinking about life on other planets. Thinking about life in Antarctica implicates a shift to thinking about "how worlds may be arrayed and organised with humans, but not only humans."17 Through our conversations over the years, we now turn our joint analytic attention to how Antarctic people inhabit Antarctic places, as cultural, material, and relational practices.

\footnotetext{
${ }^{17}$ Ben Anderson and Paul Harrison, "The Promise of Non-Representational Theories," in TakingPlace: Non-Representational Theories and Geography, eds. Ben Anderson and Paul Harrison, (Farnham, Surrey, England: Ashgate, 2010), 12.
} 
There are over one hundred facilities in Antarctica, of which eighty-two are classified as "stations" and the remainder as "camps" or "refuges". ${ }^{18}$ Human presence in Antarctic environments is limited in numbers and also highly regulated and controlled in terms of the activities that may be performed. During the last decade — since peaking in the 2007-2008 summer season at forty-six thousand visitors - close to thirty-five thousand tourists from over 30 countries have visited the fringes of Antarctica each year, mostly in the Antarctic Peninsula. Across the continent, close to a thousand people — mostly scientists and logistics support personnel—live there yearround. This number grows in summer to approximately five thousand scientists, logistics personnel, military staff, and civilians from the twenty-nine countries with consultative status under the Antarctic Treaty System. Most of these people live transiently in stations located in the South Shetland Islands (south of South America), in the Larsemann Hills area (south of the Indian Ocean), and in the Ross Sea area (south of Australia and New Zealand).

There are only two places in Antarctica that could be thought of as being similar to polar towns in the Arctic: Ross Island — by far the largest—and Fildes Peninsula on King George Island. These two settlements are critical examples of a different mode of top-down, regulated place-making, layered over informal, creative, transgressive, and improvisational bottom-up living practices of everyday Antarctic life. In both instances, infrastructures - both as built networks that facilitate the circulation of goods, people, data, and logistics, and as the coordination and control of movement of people and things along and within global supply chains-are crucial to the establishment and subsistence of these settlements. As such, infrastructure and

\footnotetext{
${ }^{18}$ Aant Elzinga, "The Continent for Science," in Handbook on the Politics of Antarctica, eds. Klaus Dodds, Alan D. Hemmings and Peder Roberts (Cheltenham: Edward Elgar, 2017), 104.
} 
logistics are deeply implicated in the making and unmaking of experiences of community, solidarity, and peculiar modes of belonging in these Antarctic settlements. ${ }^{19}$

Below, we describe everyday life in Antarctic research stations as frontier human settlements, with particular attention to how the mundane, the banal, the little facets of life intersect the sublime, the spectacular, and the unique. ${ }^{20}$ As Gupta and Ferguson note, ethnographic fieldwork's focus on “taken-for-granted social routines, informal knowledge, and embodied practices" can yield understanding that cannot be obtained through more traditional social surveys or decontextualised readings of cultural products and practices. ${ }^{21}$ Therefore, we account for the everyday life of two far-flung Antarctic locations that do not regularly interact with each other: their geographical orientation tends towards their national homes. In this comparison, we consider how Antarctic habitation orients daily life toward broader dramas of nature, nationalism, and everyday routines on the Ice.

\section{Ross Island: frontiers of bilateralism}

Traveling to Ross Island means following the traces of some notable Antarctic explorers who preceded you. Both Captain Robert Falcon Scott and Sir Ernest Shackleton prepared to travel south through Christchurch, New Zealand, and its nearby harbor town of Lyttleton. For decades, Antarctic travelers have eaten their

\footnotetext{
${ }^{19}$ Juan Francisco Salazar, "Polar Infrastructures," In The Routledge Companion to Digital Ethnography, eds. Larissa Hjorth et al. (Milton Park and New York: Routledge, 2016), 374.

${ }^{20}$ Jessica O'Reilly, "Preparing for Disaster on the Polar Frontier: An Antarctic Field Training Manual," Environmental Humanities 9, no. 2 (2017): forthcoming.

${ }^{21}$ Gupta and Ferguson, "Beyond 'Culture,"” 36.
} 
ritual predeparture dinner at Bailies Bar. ${ }^{22}$ Though almost all people traveling south from Christchurch now depart by plane, the line they draw between New Zealand and Antarctica remains virtually unchanged.

Planes land on an ice runway off the frozen coast of Ross Island. From there, a stocky, orange vehicle emblazoned with the name "Ivan the Terra Bus" picks up passengers and transports them to McMurdo Station and Scott Base. The bus is emblematic of the United States Antarctic Program: cheerful, industrious, and a bit dominating.

The bases are two kilometres from each other and are an easy study in contrasts. McMurdo Station, established in 1956 and the largest base on the continent, is run by the United States Antarctic Program and its military contractors, currently Lockheed Martin. Scott Base, established in 1957, is managed by Antarctica New Zealand and is much smaller in size, with a peak population of about 200 compared to McMurdo's 1,100 .

Many before us have portrayed McMurdo. It manages to exemplify the United States quite ably, with its optimism, chaos, frontier character, and sprawl. The buildings are cacophonous in colour and form and represent multiple eras of Antarctic construction, foregrounded by Scott's Discovery Hut in the near distance. Large dormitory blocks hug the outer rim of the station, with dining halls, research facilities, logistics buildings, and other social spaces strewn about.

\footnotetext{
${ }^{22}$ Bailies, which was located on Christchurch's city square, was destroyed in the 2011 Christchurch earthquake. The owners were able to salvage the Antarctic memorabilia and have reopened in a new location.
} 
The frequency with which McMurdo is dismissed as ugly American sprawl makes us seek out alternate storylines. ${ }^{23}$ One important one- - for it is the discourse of the Antarctic continent - is that this mega-base supports science capabilities more diverse than any other Antarctic operation. While other national bases also have state-of-theart laboratories and field operations support infrastructure, McMurdo stands out as supporting more science projects in number and discipline than any other station. Field projects can be supported anywhere on the continent from McMurdo, and the station also serves as the staging ground for the United States' Amundsen-Scott South Pole Station. Trends in the kinds of projects supported by McMurdo (and their attendant logistics) shift over time, and so it does not support scientists all over the continent each season. However, its geographic and technical reach and capability is a form of power: the power to access places that other states do not have the means to. And this, while the United States does not claim any Antarctic Territory, is a form of territory-claiming in practice.

If McMurdo is the sprawling city, Scott Base is the well-planned suburb. Following the graded road around Observation Hill—either on foot or by taking the bus that connects the two bases - you arrive at Scott Base. It is compact, with almost all of the buildings painted hospital green and interconnected. The uniform colour looks tidy, assisted by the Saturday afternoon chores that everyone on base participates in. With less of an appearance of a construction site, Scott Base is comfortable and homey.

\footnotetext{
${ }^{23}$ A similar thing can be said about the Fildes Peninsula area, King George Island, as we describe in the following section, where scientists and tourists often scorn the area for having too much of a human footprint.
} 
You can walk from your lab to the event cages ${ }^{24}$ to the dining hall to your bed without having to dress for Antarctic weather.

The size of Scott Base reflects the size of New Zealand - in per capita terms, Scott Base is a major scientific investment for New Zealand. Even so, its existence relies on a close logistical partnership with the United States. The United States-New Zealand Antarctic programmes are a cornerstone of New Zealand's bilateral relationship with the United States. The two countries share flights south. New Zealand provides a logistical point of departure in Christchurch, and the United States provides the annual ship-based resupply, which transports all of both bases' fuel supply. The New Zealand and United States Antarctic programmes have maintained a mutually beneficial relationship.

Infrastructure and bilateral agreements, though, simply form the crust of Antarctic dwelling on the Ross Sea side of the continent. Who lives there, and how do they style their daily lives (or how are these styled for them)? Who enacts these bilateral relationships and keeps the infrastructure working?

In the Antarctic stations, there is a large cohort of people in their twenties. Science teams usually have a few senior Principal Investigators with an orbit of $\mathrm{PhD}$ students and postdocs. The base support staff consists of managers, technicians, and "lifers," but many of those taking jobs with contractors are young adults seeking adventure and experience, an austral summer in the Antarctic. These are the youngest people on Ross Island. Some will return year after year, perhaps oscillating between summer in

\footnotetext{
${ }^{24}$ Event cages are fenced-off warehouse spaces for field teams and their logistics coordinators to gather together all their needed supplies before departing for their camp.
} 
the Antarctic and summer near the Arctic, pursuing work in remote places with almost endless sunlight. ${ }^{25}$

With an entirely adult population skewed toward people in their twenties, national Antarctic programmes manage and order human bodies in particularly rigorous ways. Each person heading south has to be medically qualified to go to Antarctica: for example, O'Reilly had to undergo examinations that her marginally insured, generally well, twenty-five-year-old body had never experienced: an electrocardiogram, a chest X-ray, and a full panel of blood tests for sexually transmitted infections. O'Reilly's research team leaders also took the group on a long mountain hike in New Zealand's Southern Alps early on in their training to ensure that they were physically capable of relatively strenuous exertion. With official seals of approval on their healthy and able bodies, residents of McMurdo Station and Scott Base tend to be athletic, energetic, and for some, sexually permissive.

Women are not permitted to be pregnant in this part of Antarctica. Pregnancy immediately disqualifies a woman from going south, and if she is already on base, she is returned to the United States or New Zealand as soon as practical. These programmes do not consider their medical teams to be adequate or tasked toward prenatal care, and pregnancy itself is seen as too risky to undertake in the Antarctic. Children are also not permitted on bases, with an exception made for tourists.

Tourists, though, are begrudgingly accepted in the Ross Island stations. There is very little tourism in this area due to its remoteness, in contrast with the Antarctic

\footnotetext{
${ }^{25}$ O'Reilly has run into some of them in Nome, Alaska, and in Ely, Minnesota.
} 
Peninsula. Some small operators sail out of New Zealand, though, and undertake the standard permitting required through their governments to visit bases and other sites of national or historical significance.

Occasionally, there are also adventurers who arrive without permits. These people cause official consternation and unofficial interest. Oftentimes, these people are notable explorers conducting a high-profile expedition, at times getting themselves into a spot of trouble with ice, weather delays, or a lack of fuel. The American government is particularly emphatic about not using their resources to help people who are not properly authorised to be in Antarctica. Wrapped up in this posture are concerns about liability, opening up the region to tourism, environmental considerations, the preservation of the Antarctic as a zone of science, and wanting to provide disincentives to underprepared and unsanctioned visitors. The United States will eventually help out a stranded traveller, but the bill follows, always to the tune of tens of thousands of dollars. The United States' approach to emergency services is often mentioned with alarm by non-governmental New Zealanders. In New Zealand, any adventurer in their country who becomes injured or lost or find themselves in the wilderness beyond their abilities is rescued and provided medical services, free of charge.

Antarctic management of bodies also extends to animal bodies, with similar themes of containment and risk mitigation. Along with the publications described below, people heading south with Antarctica New Zealand are given a flyer about their "Antarctic environmental code of conduct." Scientists studying animals have their research scrutinised by their institutional ethics boards and their national Antarctic 
programmes. Other people encountering wildlife in Antarctica are expected to keep at least five metres distance from penguins and other biota. However, there is a vibrant set of folk practices passed around to encourage wildlife to approach people, since animals do not have to comply with the regulation. People out in the field may try mimicking penguins or seals to try to attract curious animals.

Station life has a structure to it. It is regimented and procedural, based on paramilitary histories and institutional risk management. ${ }^{26}$ People traveling south with Antarctica New Zealand receive a set of official publications, each updated annually: the Antarctica New Zealand Handbook (covering basic information and procedures in terms of life at Scott Base), the Antarctica New Zealand Field Manual (for those working at field sites; at the back of the book is a comprehensive first-aid guide, with information, for example, on amputations and how to use a ski to brace a broken leg), and the Antarctica New Zealand Recipe Book (a brief, fantastic overview of highcalorie Kiwi camping food, with each recipe attributed to a New Zealand Antarctic scientist). O'Reilly's book set, from the 2005-2006 field season, are covered with beautiful photographs of Antarctic lichen taken by Catherine Beard, and a photo of biscuits and a can of Bird's Baking Powder that the Scott Expedition left behind in their hut. The books encapsulate history, tradition, nationalism, and the application of governmental oversight onto individualistic wilderness risk management.

Social activities, formal and informal, abound on Ross Island. In a post to the Idle Words blog on May 16, 2016, blogger Maciej Ceglowski described the McMurdo residence halls as reminiscent of 1990s-era college dormitories with their amenities

\footnotetext{
${ }^{26}$ O'Reilly, "Preparing for Disaster," forthcoming.
} 
and lack of wireless Internet or cell phone service. ${ }^{27}$ Residents organise sporting events, such as United States and New Zealand rugby team competitions. Other events include a January music festival called Icestock, and theme parties. The environment is both ignored (for example, toga parties do not emerge from particular Antarctic environmental relationships) and treated as recreational, as residents go skiing, camping, on walks, or on the rare recreational excursion or logistics ride-along afforded to station employees who put themselves on a waiting list. The Antarctic environment, when framed as backdrop or recreation ground, reflects Western environmental philosophies generally, though people living at the base may describe their personal environmental philosophies with more complexity.

While recreational activities are both planned and spontaneous, a great deal of cultural improvisation occurs at McMurdo Station and Scott Base. Some of these activities, like those described by Nicholas Johnson in his memoir, are explicitly countercultural, wary of the paramilitary contractors, and benignly exploitative of the system's weaknesses and gaps, with the Antarctic station employee a contemporary extension of John Yossarian from the novel Catch-22. ${ }^{28}$ While Antarctic life on Ross Island is highly structured through the national Antarctic programmes, residents engage in casual and humorous resistance to these structures even as they adhere to them. For example, in Johnson's account, the McMurdo baker goes on an unofficial strike, only putting out prepackaged baked goods due to a lack of appreciation of her more artisanal efforts (Johnson notes that the baker for the historical Byrd expedition went on a similar strike to protest too much partying from the team); a worker

\footnotetext{
${ }^{27}$ Maciej Ceglowski, "Shuffleboard at McMurdo," Idle Words (blog), May 15, 2016, http://idlewords.com/2016/05/shuffleboard_at_mcmurdo.htm.

${ }^{28}$ Nicholas Johnson, Big Dead Place: Inside the Strange \& Menacing World of Antarctica (Los Angeles: Feral House, 2005); Heller, Catch-22 (New York: Simon \& Schuster, 1961). Yossarian as a literary figure casually resisted and exploited the military bureaucracy he was a part of.
} 
considers noncompliance with the housing policies, though backs down eventually in the face of a fine; and a disgruntled group publishes underground station newspapers. ${ }^{29}$ As a captive audience, station employees navigate the complex management landscape with varying degrees of creativity and compliance.

A final characteristic of human Antarctic life at Ross Island cannot go without mention. When O'Reilly began researching Antarctica in graduate school in the early 2000s, one of her mentors remarked that "Antarctica is white, in more ways than one." ${ }^{30}$ While this is not true of every research station on the continent, due to its growing national diversity, it is certainly true of McMurdo Station and Scott Base. Not all, but most of the station employees - and scientists - are of European ancestry, a legacy of the long and close relationship between colonialism and exploration in European history as well as stemming from the racialised and ethnic trends of diversity (or lack thereof) in natural and physical scientific research and the notion of wilderness as a site of leisure and recreation for white, middle-class people in the United States and New Zealand. ${ }^{31}$

People living and working on Ross Island are practicing bilateral relationships, a diplomatic relationship made real through the sharing of everyday lives in a space where the distance between New Zealand and the United States is tightly compressed and bound by shared interests. This embodied bilateralism is formed by perfectly able bodies, trending towards young adulthood in a quasi-communal, highly regimented, and procedural living situation.

\footnotetext{
${ }^{29}$ Johnson, Big Dead Place, 198, 206, 209.

${ }^{30}$ Thanks to Susan Harding.

${ }^{31}$ Floyd, Myron, "Race, Ethnicity and Use of the National Park System," Social Science Research Review 1, no. 2 (1999): 1-24.
} 


\section{King George Island: non-sovereign national enclaves on Ice}

Ross Island and King George Island have been historically the two main gateways into the Antarctic, and remain so today. Like in the case made in the previous section with Ross Island, traveling to King George Island also entails following the traces of some notable Antarctic explorers who crossed the dire waters of the Drake Passage to reach the South Shetland Islands, from where Antarctica was discovered in the summer of 1819-1820 and where a group of sealers is thought to have had wintered on King George Island in the South Shetlands in 1821. Among the most notorious of explorers were Adrien de Gerlache leader of the Belgian Antarctic Expedition (18971901), which was notable for being the first expedition of a purely scientific nature, and the first one to overwinter in Antarctica when their ship, the RV Belgica became trapped in ice in the winter of $1898^{32}$; and Sir Ernest Shackleton, leader of the failed Imperial Trans-Antarctic Expedition (1914-17), also known as the Endurance Expedition, which is often regarded as one of the last major expeditions of the Heroic Age of Antarctic Exploration.

However, different to the case of Ross Island, this area of the Antarctic Peninsula is notable for being a disputed space between Chile, Argentina, and Britain over territorial claims in the Antarctic Peninsula, which date back to the first decades of the twentieth century in what become known in the 1950's as the "Antarctic

\footnotetext{
32 Coincidentally, scientists on this expedition were the first to describe the Antarctic midge, or Belgica antarctica, the only insect endemic to Antarctica, the first Antarctic eukaryote to be sequenced, and the same insect that the Chilean microbiologists and ecologists we interviewed were studying for its responses to extreme temperatures, freeze tolerance, osmotic stress, ultraviolet radiation and other forms of environmental stress considering it has the smallest insect genome sequenced to date.
} 
Problem". Interestingly, in the period 1939-1959 — as Adrian Howkins has notedone of the most remarkable features of the Antarctic sovereignty dispute between Britain, Argentina, and Chile was that the three countries would be fighting over a virtually unknown territory. ${ }^{33}$

Since the 1980s King George Island, with a polar tundra climate, no true summer, and an annual average temperature of -2.3 degrees Celsius, has become a primary space of coordination and control of a range of Antarctic logistical, scientific, and tourism activities. In fact, Fildes Peninsula on King George Island has become a key logistics centre for the northern Antarctic Peninsula, a place where the operations of several countries come together.

The island is host to sixteen research stations as well as the Chilean military-civilian settlement of Villa Las Estrellas on Fildes Peninsula, which hosts several families, a school, a hospital, a gym, and the well-known Russian Orthodox Holy Trinity Church, adjacent to the Russian Bellingshausen Station. The area is home to about two hundred inhabitants year-round and up to seven thousand people in summer, who include scientists, tourists, trade workers, and other visitors. King George Island and the rest of the South Shetland Islands are an important a hotspot of land-based tourism development. ${ }^{34}$ Most importantly, the South Shetland Islands and the northern part of the Antarctic Peninsula today comprise the most accessible Antarctic region, accounting for one of the highest levels of seasonal occupation by scientific parties in

\footnotetext{
${ }^{33}$ Howkins, Adrian. Frozen Empires: A History of the Antarctic Sovereignty Dispute Between Britain, Argentina, and Chile, 1939-1959, PhD Dissertation, The University of Texas at Austin, 2008.

${ }^{34}$ Daniela Liggett et al.," "From Frozen Continent to Tourism Hotspot? Five Decades of Antarctic Tourism Development and Management, and a Glimpse Into the Future," Tourism Management 32, no. 2 (2011): 358 .
} 
Antarctica, and arguably one of the largest concentrations of scientific research activities in the world.

In the Fildes Peninsula area of King George Island, there are six permanent research stations plus the Teniente Marsh airstrip, built by the Chilean Air Force in 1980 and currently administered by Chile's Dirección General de Aeronáutica Civil (DGACCivil Aeronautical Office). These are Russia's Bellingshausen station, built in 1968 with the famous Trinity Church erected in 2004; Chile's Base Presidente Eduardo Frei Montalva, established in 1969 and occupied by the Chilean Air Force with its adjacent civilian settlement of Villa Las Estrellas established in $1984^{35}$; the South Korean King Sejong Station (established in 1988); the Chinese Great Wall Station (1985; Uruguay's Artigas Station (1984); and Chile's Julio Escudero research station (1995), established by the Chilean Antarctic Institute (INACH). ${ }^{36}$ In a range of ways, Fildes Peninsula on King George Island is an example of how Chile in particular (but not unlike like all Antarctic Treaty System nations) has used Antarctica to further a range of domestic and international projects.

\footnotetext{
${ }^{35}$ To date there are only two stations that accommodate a small civilian population including families and children. One is the Chilean Villa Las Estrellas (just over one hundred residents in summer and around eighty in winter) The other is the Argentinian Esperanza base (fifty-five winter residents) at Hope Bay on the northern tip of the Antarctic Peninsula. Both have a school, medical facilities, and gyms, used by families of military officials or who come with their Antarctic employee. In both cases during heightened tension in the South Atlantic between Argentina and Chile prior to and immediately after the Malvinas/Falklands war, the respective countries' governments planned these stations to make explicit claims of Antarctic settlement as insurance in the case that the Antarctic Treaty would need to be renegotiated in the future. In both instances, several women in their later stages of pregnancy were sent there to give birth to "native Antarcticans" in the case this might support such claims. None of these five Argentinean and three Chilean nationals born in Antarctica lived for more than a few months or years in Antarctica.

36 These six stations are also close to other research stations in the island that also share the logistics of the Marsh airfield and are linked by radio communications. These include Argentina's Carlini Base formerly known as Jubany Base until 2014 and emplaced on a site where an initial refuge was established on 21 November 1953; Poland's Arctowski Station (1977), Brazil's Commandante Ferraz Station (1984) and Peru's Machu-Picchu Station.
} 
These six stations are networked through a road or accessible by Zodiac (an inflatable, motorised dinghy) and linked through UHF and VHF radio (which also extends to Argentina's Carlini station) and in the shared use of the airfield. Similarly to the case of McMurdo and Scott Base, the airfield plays a pivotal role in understanding mobility. In the case of the Teniente Marsh airstrip, it is interesting to note how personnel from Antarctic Airways and from the Russian, Chinese, US, South Korean, Brazilian, Argentinean, Uruguayan, and Chilean bases gather here, especially in summer, in their SUVs and trucks sporting their national flags. In all its apparent dullness, the airfield acts as a crucial interface in the regulation of mobility to and from Antarctica. The Marsh Airfield operates close to two thousand flights in a single year, moving several thousand travellers (civilian and military) to and from King George Island to South America and other bases in Antarctica. It is a site of circulating knowledge connecting Antarctica with the outside, as well as with several national field stations on King George Island and further into the Antarctic mainland.

King George Island, in contrast to the relative ethnic homogeneity of McMurdo Station and Scott Base, is a highly multicultural and international space. Our ethnographic fieldwork there has confirmed this sense of internationalism and cooperation among stationed personnel. In addition, and contrary to the previous case, pregnancy does not necessarily disqualify women from staying on the island, and despite the high number of young doctoral and early-career scientists, the entirely adult population is not skewed toward people in their twenties.

The national Antarctic programmes operating here, in addition to the Chilean, Argentinean, Brazilian, Uruguayan air forces and navies, do regiment and order 
human bodies and activities, but not to the same extent as in the Ross area. Chilean Air Force officials are in fact allowed to live there for two or three years with their families, their children attending the Villa Las Estrellas School, administered by the Chilean Ministry of Education.

People in Fildes Peninsula live across different time zones in less than three square kilometres. One can often hear them greeting each other in four languages. In summer, a mother can be seen strolling her baby along the bay, while a Russian Orthodox priest rings church bells to summon the faithful to services. Tourists walk up and down the bases taking pictures, which they upload straightaway to Facebook, Twitter, and Instagram due to the mobile telephony tower erected by the Chilean private company Entel in 2005, providing connectivity to the hundreds of people that visit during the summer or to the area's longer-term residents who spend their winters here. ${ }^{37}$ People don't rely on the use of money except when buying stamps or souvenirs at the post office. All food, clothing, and health services are provided free of cost by the National Antarctic Programmes or the Armed Forces. An interesting system of reciprocity and gift exchange is informally and efficiently at play. Gift exchange is very significant fore instance when chiefs of stations visit each other's stations or receive visitors from off the island. Unlike other forms of reciprocity and gift exchange as studies prominent in the anthropological literature, in the Antarctic case there is a horizontal rather than a hierarchical relationship. Science research stations, especially in King George Island, effectively operate as national enclaves. Anne-Marie Brady has used the term "embassies on Ice". ${ }^{38}$ While scientific and

\footnotetext{
${ }^{37}$ For a more detailed account of Antarctic telecommunications infrastructure, see Salazar, "Polar Infrastructures."

38 Anne-Marie Brady quoted in BBC News Magazine article 'How Antarctic bases went from wooden huts to sci-fi chic', 17 January 2017, http://www.bbc.com/news/magazine-38574003
} 
logistical practices are the common denominator, it is interesting to see how each of the stations and bases operates as a kind of non-sovereign semi-enclaves to showcase a nation's interests in Antarctica and promote national culture and boast scientific pedigree.

One of the most interesting periods in the calendar for this area is during the first week of February in the middle of summer, when scientists, logistics personnel, visitors, tourists, teachers, parents, and sometimes children (from the only public school in the area, the Chilean F-50 public school) gather for celebratory parties to commemorate the establishment of their bases. Many of these bases were established during the summer thus for a few weeks in late January and early February, cultural diplomacy become as important as scientific work. At China's Great Wall station for instance, these celebrations often coincide with Chinese New Year and on occasions a dragon has been seen parading in the ice. In most cases Special foods (fresh fruit and scarce treats) are brought to the stations and bases purposely from Punta Arenas in Chile for the occasion and prepared and shared communally; in some instances people sing folks songs and play traditional games. One can witness a jolly camaraderie among men and women, older people and children — who in many cases communicate with each other with their hands or drawings to cross linguistic barriers-for a brief moment transcending the nationalism implicit in all these events. The political effect of these anniversary celebrations cannot be underestimated in the creation not only of mutual obligations but also of prestige and in the promotion of national activities and 
interests in the region. They are a manifestation of Antarctic nationalism on the ground..$^{39}$

During the summer season the area is full of tourists, who are often viewed begrudgingly by scientists because they can disrupt their work. ${ }^{40}$ Life in the winter months (March to November) is far more difficult due to the extreme climatic conditions of the area. Short days and lack of sunlight, temperatures dropping down to -30 degrees Celsius, whiteouts, and strong windstorms may cause psychological pressure, and some interlocutors reported periods of depression, especially in children living there for over two years.

\section{Discussion}

Australian author Meredith Hooper wrote an account of "all the things that make up Palmer Station and its surroundings: its animals, weather, landscape, peoples, humanmade objects, and the ideas that suffuse and give meaning to all those things and their relationships with each other." 41 The people living on Ross and King George Islands do not only inhabit their places in ways that reflect histories of colonialism and imperial expansion, conform to the silent norms of science and diplomacy, or are shaped and bounded by extreme ecological and environmental conditions. Their social lives are also shaped by the interest in creating human communities out of a landscape often considered uninhabitable.

\footnotetext{
${ }^{39}$ See Hemmings, Alan D., Sanjay Chaturvedi, Elizabeth Leane, Daniela Liggett, and Juan Francisco Salazar. "Nationalism in Today's Antarctic." The Yearbook of Polar Law Online 7, no. 1 (2015), 531.

${ }^{40}$ For more detail, see Juan Francisco Salazar, "Afterword: Polar Worlds: Arctic and Antarctic Visions," in Green Ice: Tourism Ecologies in the European High North: Green Ice, Simone Abram and Katrín Anna Lund (eds.) (London: Palgrave MacMillan), 2017a, 97.

${ }^{41}$ Meredith Hooper, The Ferocious Summer: Adélie Penguins and the Warming of Antarctica (Vancouver, BC: Greystone Books, 2008). See also Alessandro Antonello, "Life, Ice and Ocean: Contemporary Antarctic Spaces," in Handbook on the Politics of Antarctica, eds. by Klaus Dodds, Alan D. Hemmings, and Peder Roberts (Cheltenham: Edward Elgar, 2017).
} 
Drawing on the work of James Clifford we observe that travel, movement, and transient modes of living, as opposed to locality, fixity, and place, shape the ways that people inhabit Antarctica. ${ }^{42}$ This perspective allows us to move away from more classic approaches to Antarctic spatialities that focus on place names and maps, which ultimately only underscore the colonial legacy of the occupation of Antarctica by nation-states with political and economic interests in the region and sufficient logistical capability to operate there. Place names and maps might in fact obscure the material politics of place and everyday life in Antarctic settlements and scientific research stations, which is in fact what we aim to bring to the fore.

When travel to and from Antarctica is untethered and regarded as a complex and pervasive condition of possibility of human experience of the place, we can argue that, differently to the rest of planet, routes precede roots in Antarctica. Data collected through extensive ethnographic interviews indicate that people for instance speak repeatedly about being inside or outside Antarctica. Again drawing on Clifford, practices of displacement in Antarctica then emerge as "constitutive of cultural meanings rather than as their simple transfer or extension". ${ }^{43}$ Antarctic places are inhabited through, rather than by, restless movements of people and things.

Our intention in this article is to draw a first comparative ethnographic analysis between the Ross Island and King George Island in order to describe processes like

\footnotetext{
42 James Clifford, Routes: Travel and Translation in the Late Twentieth Century (Cambridge, MA and London: Harvard University Press, 1997), 3.

${ }^{43}$ Clifford, Routes, 3
} 
the "taking-place" of everyday practices in Antarctic settlements, the affective links to these places, and the performative nature of Antarctic sovereignty.

The contribution of our intermittent ethnographic work in the Antarctic is beginning to show the different modes of understanding ways of inhabiting the Antarctic. On the one hand there are particular populations of bodies that differ in composition among bases where people at and among the bases perform particular forms of political relationships and are governed by specific technological relationships that vary by location, feasibility, and human labour. On the other hand people develop particular attachments to the Antarctic natural environment, which are simultaneously conventional and everyday, as well as positioned in reference to the exceptional ecosystems in which they live.

Antarctic human bodies, especially in the Ross Sea are, are managed like virtually nowhere else on Earth, with biomedical and psychological scrutiny and very little in the way of accommodation for bodies that do not meet set standards. While some of these populations and relationships emerge through particular policy directions in national Antarctic programmes, we suggest that everyday encounters, in particular, lend power, meaning, and shape to Antarctic life. The everyday-ness of living a life (or part of one's life) in Antarctica helps routinize relationships and perform placemaking, even—or especially—when these run counter to official guidelines. Ethnographic accounts of human life in Antarctica must be developed not only considering who these humans are but also around what they do. As the art curator Annick Bureaud observes, Antarctica today "is much more than just the sign of appropriation via symbolic marking or the playground of heroic expeditionary 
figures". ${ }^{44}$ However, the endless imaginary of the sublime and untouched Antarctic wilderness overpowers the fact that new forms of social life are emerging there alongside non-human life forms that have been there for millennia. The ordering of these new human forms of life straddles the boundaries between liberation and control, as if new biological frontiers expand human potential but only for limited, managed populations.

The geopolitical arrangements in Antarctica, while negotiated in meeting rooms filled with diplomats, scientists, and military personnel elsewhere, take on a peculiar domesticity on the "Ice". On Ross Island, New Zealanders and Americans share some logistics and socialise freely, operationalising the friendly, cooperative relationship in practice and in daily life. King George Island pulls together over twenty nations into a small space, creating a working polar equivalent of utopian global fantasies typically only realised at World's Fairs and Epcot.

Antarctic people embody geopolitics in the mundane gestures of sharing transportation, attending each other's celebrations, and getting together in dining halls. These practices are bottom-up, filtering back up into the relatively collegial and cooperative Antarctic Treaty meetings.

The Antarctic environment, depicted for faraway audiences as spectacular, dangerous, and otherworldly, also becomes refocused when observed through everyday human life. The disruption of human activity in Antarctica is abundantly clear: in these fragile, diverse, often pristine ecosystems, small human traces like footprints can

\footnotetext{
${ }^{44}$ Annick Bureaud, "Inhabiting the Extreme or Making Antarctica familiar," in Far Field: Digital Culture, Climate Change, and the Poles, eds. Jane Marsching and Andrea Polli (Bristol and Chicago: Intellect Books, 2012), 193.
} 
appear glaringly out of place. People living in the Antarctic relate to its environment in diverse ways - with awe, with respect, with desire for intimacy (as scientists try to get seals and penguins to approach them), and with frustration as life is disrupted through whiteouts or katabatic winds. The spectacular, remote wildness of Antarctica from a distance becomes lived and worked with, through, and in spite of.

As we have pointed out earlier, a different conceptual vocabulary might be required to account for these Antarctic spaces and places. ${ }^{45}$ On the one hand, Antarctic places do not entirely fit with the definition of "cold colonies" as they are not self-sufficient settlements from where further settlements are established further inland. All life in this places, from food, to energy, to satellite communications, to the movement of people and infrastructure, is intricately connected to global supply chains that link Antarctic places to several cities and regions across the globe. Similarly, Antarctic places are not sites for natural resource extraction and their relationship to the metropole relates more closely to international diplomatic concerns about sovereignty and the transnational work of scientific knowledge production.

On the other hand, Stephen J. Pyne has asserted that because Antarctica is “inextricably different" and quasi-extraterrestrial in its lack of sustenance for human life, it is often a used as a proxy or surrogate for the exploration and colonisation of space. As Pyne notes, "more than a century of Antarctic experience [...] suggests that exploration will likely resemble the Renaissance's Great Voyages and their outposts rather than become portals for wholesale colonization". ${ }^{46}$ This might suggest that Antarctic settlements will continue to be mostly logistical nodes for (scientific) data

\footnotetext{
${ }^{45}$ Salazar, "Geographies of Place-making," 61.

${ }^{46}$ Stephen Pyne, "The Extraterrestrial Earth: Antarctica as Analogue for Space Exploration," Space Policy 23, no. 3 (2007): 147.
} 
traffic - what Pyne notes might be an early twenty-first century's equivalent of spices, raw materials, and luxury goods. We beg to disagree. While we are still far away from describing a new "true" civilisation, in the Ross Sea area and in the Antarctic Peninsula, however one defines it, the reality of life there is far from being "mere outposts". In his account of Antarctic settlements Tom Griffiths has written of "a peculiar civilisation where the workings of history might be laid bare" 47 which we think resonates more with our ethnographic accounts.

\section{Conclusions}

Accounts of life in Antarctica come from a range of fieldnotes and diaries of ethnographers, historians, artists, writers, and journalists. All of these are important parts of a fluid mosaic of everyday life in Antarctica and show that Antarctica is no longer completely alien to human habitation as it once was as novel socialities begin to emerge across a range of Antarctic places.

A first aim of this article has been to call attention to how a polar anthropology might theorise these places as they embody and enact relations of scale and connectivity in ways that only make them productive for scientific and geopolitical capital, but point to how humans are making themselves at home in extreme environments.

Acknowledging that the operation of scientific research forms the key goal of national Antarctic programmes, we still think these territories are becoming something more than sites for organising logistical operations in support of science and deserve attention as experiments of human dwelling in extreme environments in ways that might pre-empt human inhabitation of Outer Space. In other words, what sparked our

\footnotetext{
${ }^{47}$ Tom Griffiths, "The Cultural Challenge of Antarctica: The 2007 Stephen-Murray Smith Memorial Lecture," The La Trobe Journal 82 (2008), 6.
} 
initial interest in writing this article was to instigate an interest in researching anthropologically these worlds to come in Antarctica.

While anthropological interpretations of imagined and outer space worlds are not new, we think more ethnographic accounts of Antarctic everyday life will be productive to gain a better sense of what are these "Antarctican" communities in the making and to_offer a glimpse into what Antarctica is becoming. Many of those who might be regarded as "true Antarcticans" are probably not the scientists or military personnel stationed there for a few years: they are the logistics support personnel (almost exclusively male), some of whom go back year after year. ${ }^{48}$ Whether a distinct polity will ever form in Antarctica during this century remains improbable, particularly as there are several increasingly influential views pushing to keep human activities restricted and in some cases replaced with remote sensing technologies, we think it is not impossible. However, the problem remains of how to understand the emergent polity of Antarctica, and as John Keane has observed, "why its break with the language and politics of sovereignty is of global significance". ${ }^{49}$

A second and related aim of this article has been to briefly discuss the expediency of ethnographic accounts of Antarctic places and people, which we hope may lead to further anthropological insights that may in turn have a wider impact. Despite Tim Ingold recently arguing that one thing preventing anthropological insights "from

\footnotetext{
${ }^{48}$ One notable case is Alejo Contreras, interviewed by Salazar in Fildes Peninsula in 2014, who has been returning to Antarctica for 6 months each year for thirty-three consecutive years. A glimpse of his life in Antarctica appears in the feature-length documentary film Nightfall on Gaia, produced and directed by Salazar (2015) based on his fieldwork in 2012-2014 and available at https://vimeo.com/117241386. See also Juan Francisco Salazar, "Speculative Fabulation: Modes for Researching Worlds to Come in Antarctica," in Anthropologies and Futures: Researching Uncertain and Emerging Worlds, eds. Juan Francisco Salazar et al. (London: Bloomsbury, 2017c).

${ }^{49}$ Keane, John. "Antarctica: Notes on the fate of sovereignty." Aurora Journal 35, no. 1 (2015): 22.
} 
having the wider, transformative effects that we might hope for them" is the "the constant resort to ethnography", ${ }^{50}$ we think that a polar anthropology project is at once ethnographic, political, and epistemological. Hence, we see the value of ethnographic research in Antarctica as part of a wider project of polar anthropology that aims to illuminate the relational dynamics that hold existing ways of thinking, doing, and acting in Antarctic places in relation to the region's specific contexts, which include the practice of science and the geopolitical and commercial interests of nation-states, non-state actors, and private corporations.

\section{Acknowledgments}

We wish to thank the two anonymous reviewers and Peter Schweitzer for inviting us to contribute to this special issue on polar anthropology. Juan Francisco Salazar wishes to thank José Retamales and Elias Bartivevic at the Instituto Antárctico Chileno (INACH) for supporting the fieldwork in Julio Escudero Base during three consecutive summer seasons.

\section{References}

Anderson, Ben, and Paul Harrison. "The Promise of Non-Representational Theories." In Taking Place: Non-represenational Theories and Geography, edited by Ben Anderson and Paul Harrison, 1-34. Farnham, Surrey, England: Ashgate, 2010.

Antonello, Alessandro. "Finding Place in Antarctica." In Antarctica and the Humanities, edited by Peder Roberts, Lize-Marié van der Watt, and Adrian Howkins, 181-203. London: Palgrave Macmillan, 2016.

Antonello, Alessandro. "Life, Ice and Ocean: Contemporary Antarctic Spaces." In Handbook on the Politics of Antarctica, edited by Klaus Dodds, Alan D. Hemmings, and Peder Roberts, 167-182. Cheltenham and Northampton, MA: Edward Elgar, 2017.

\footnotetext{
50 Tim Ingold, “That's Enough About Ethnography!,” 392.
} 
Bureaud, Annick. "Inhabiting the Extreme or Making Antarctica Familiar." In Far Field: Digital Culture, Climate Change, and the Poles, edited by Jane Marsching and Andrea Polli, 188-199. Bristol and Chicago: Intellect Books, 2012.

Clifford, James. Routes: Travel and Translation in the Late Twentieth Century. Cambridge, MA and London: Harvard University Press, 1997.

Collis, Christy, and Quentin Stevens. "Cold Colonies: Antarctic Spatialities at Mawson and McMurdo Stations." Cultural Geographies 14, no. 2 (2007): 234-54.

Elzinga, Aant. "The Continent for Science." In Handbook on the Politics of Antarctica, edited by Klaus Dodds, Alan D. Hemmings and Peder Roberts, 103-124. Cheltenham, UK: Edward Elgar, 2017.

Hemmings, Alan D., Sanjay Chaturvedi, Elizabeth Leane, Daniela Liggett, and Juan Francisco Salazar. "Nationalism in Today's Antarctic." The Yearbook of Polar Law 7, no. 1 (2015): 531-555.

Floyd, Myron. "Race, Ethnicity and Use of the National Park System." Social Science Research Review 1, no. 2 (1999): 1-24.

Glasberg, Elena. Antarctica As Cultural Critique: The Gendered Politics of Scientific Exploration and Climate Change. New York: Palgrave-Macmillan, 2012.

Griffiths, Tom. "The Cultural Challenge of Antarctica: The 2007 Stephen-Murray Smith Memorial Lecture." The La Trobe Journal 82 (2008): 4-14.

Gupta, Akhil, and James Ferguson. "Beyond 'Culture': Space, Identity, and the Politics of Difference." In Culture, Power, Place: Explorations in Critical Anthropology, edited by Akhil Gupta and James Ferguson, 33-51. Durham and London: Duke University Press, 1997.

Hastrup, Kirsten. "Anticipating Nature: The Productive Uncertainty of Climate Models". In The Social Life of Climate Change Models: Anticipating Nature, edited by Kirsten Hastrup and Martin Skrydstrup, 1-29. London and New York: Routledge, 2013.

Heller, Joseph. Catch-22. New York: Simon \& Schuster, 1961.

Hooper, Meredith. The Ferocious Summer: Adélie Penguins and the Warming of Antarctica. Vancouver, BC: Greystone Books, 2008.

Howkins, Adrian. The Polar Regions: An Environmental History. Cambridge, UK: Polity, 2016.

Howkins, Adrian John. Frozen Empires: A History of the Antarctic Sovereignty Dispute Between Britain, Argentina, and Chile, 1939--1959. PhD Dissertation. University of Texas, 2008. 
Ingold, Tim. “That's Enough About Ethnography!” HAU: Journal of Ethnographic Theory 4, no. 1 (2014): 383-95.

Johnson, Nicholas. Big Dead Place: Inside the Strange \& Menacing World of Antarctica. Los Angeles: Feral House, 2005.

Keane, John. "Antarctica: Notes on the fate of sovereignty." Aurora Journal 35, no. 1 (2015): 22.

Liggett, Daniela, Alison McIntosh, Anna Thompson, Neil Gilbert, and Bryan Storey. "From Frozen Continent to Tourism Hotspot? Five Decades of Antarctic Tourism Development and Management, and a Glimpse Into the Future." Tourism Management 32, no. 2 (2011): 357-66.

Massey, Doreen. For Space. Los Angeles and London: SAGE, 2005.

O'Reilly, Jessica. The Technocratic Antarctic: An Ethnography of Scientific Expertise and Environmental Governance. Ithaca, NY: Cornell University Press, 2017.

O'Reilly, Jessica. "Preparing for Disaster on the Polar Frontier: An Antarctic Field Training Manual." Environmental Humanities 9, no. 2 (2017): forthcoming.

Pyne, Stephen J. "The Extraterrestrial Earth: Antarctica as Analogue for Space Exploration." Space Policy 23, no. 3 (2007): 147-149.

Salazar, Juan Francisco. "Geographies of Place-making in Antarctica: An Ethnographic Approach.” The Polar Journal 3, no. 1 (2013): 53-71.

Salazar, Juan Francisco. "Polar Infrastructures." In The Routledge Companion to Digital Ethnography, edited by Larissa Hjorth, Heather Horst, Anne Galloway, and Genevieve Bell, 374-83. Milton Park and New York: Routledge, 2016.

Salazar, Juan Francisco. "Afterword: Polar Worlds: Arctic and Antarctic Visions." In Green Ice: Tourism Ecologies in the European High North, edited by Simone Abram and Katrin Anna Lund, 97-114. London: Palgrave Macmillan, 2017a.

Salazar, Juan Francisco. "Mediating Antarctica in Digital Culture: Politics of Representation and Visualization in Art and Science." In Handbook on the Politics of Antarctica, edited by Klaus Dodds, Alan D. Hemmings, and Peder Roberts, 125-141. Cheltenham, UK: Edward Elgar, 2017b.

Salazar, Juan Francisco. "Speculative Fabulation: Modes for Researching Worlds to Come in Antarctica." In Juan Francisco Salazar, Sarah Pink, Andrew Irving, and Johannes Sjöberg, Anthropologies and Futures: Researching Uncertain and Emerging Worlds, 151-170. London: Bloomsbury, 2017c.

Stewart, Kathleen. “Atmospheric Attunements.” Environment and Planning D: Society and Space 29, no. 3 (2011): 445-53. 
Valentine, David, Valerie A. Olson, and Debbora Battaglia. "Extreme: Limits and Horizons in the Once and Future Cosmos." Anthropological Quarterly 85, no. 4 (2012): 1007-26. 